\title{
Karakterisasi material mesopori Ni/MCM-41 dan pengaruh penambahan logam nikel terhadap tingkat keasaman material
}

\author{
Soenandar Milian Tompunu Tengker ${ }^{* a}$,Jenny Kumajas ${ }^{a}$ \\ a Kimia, Universitas Negeri Manado, Minahasa, 95618, Indonesia
}

INFO ARTIKEL

Diterima 20 Agustus 2019

Disetujui 26 Oktober 2019

Key word:

Ni/MCM-41,

Mesopore material

Nickel

Kata kunci:

Ni/MCM-41,

Material Mesopori

Nikel

\section{A B S T R A C T}

The pure MCM-41 mesoporous material cannot be used directly as a catalyst, so metals or nonmetals need to be added to create an acidic side. Nickel is a metal that is Lewis acid because it is able to accept lone pairs of electrons from ligands to form complex compounds. The purpose of this study was to produce Ni/MCM-41 mesoporous material and see the effect of the addition of Nickel metal to the acidity level of Ni/MCM-41 mesoporous material. The method used is the ion exchange method to produce Ni/MCM-41 and gravimetric method to test the acidity of the material. The MCM-41 used for Ni/MCM-41 synthesis has an $x$-ray diffraction pattern with an hexagonal structure that is identical to the results of the MOC researchers. BET results showed Langmuir type IV adsorption isotherm with a surface area of Ni / MCM-41 material of $775.9 \mathrm{~m} 2 / \mathrm{g}$, pore volume of 0.81 $c c / g$ and pore radius of $15.2 \AA$. TEM characterization shows the morphological shape of Ni/MCM-41 in the form of hexagonal structure. The acidity test results of Ni/MCM-41 material have a higher acidity level compared to MCM-41. Based on the research data, it can be concluded that Ni/MCM-41 has a morphological form with a hexagonal structure, has a large surface area and has a pore size classified as mesoporous material and has a higher acidity level than the MCM-41 synthesized.

\footnotetext{
*e-mail:

soenandarmilianttengker@unima.ac.id *Telp:

(+62) 85256544641
}

\section{A BSTRAK}

Material mesopori MCM-41 tidak dapat digunakan langsung sebagai katalis, sehingga perlu ditambahkan logam atau bukan logam untuk menciptakan sisi asam. Nikel merupakan logam yang bersifat sebagai asam Lewis karena mampu menerima pasangan elektron bebas dari ligan untuk membentuk senyawa kompleks. Tujuan penelitian ini adalah untuk menghasilkan material mesopori Ni/MCM-41 dan melihat pengaruh penambahan logam Nikel terhadap tingkat keasaman material mesopori Ni/MCM-41. Metode yang digunakan yaitu metode pertukaran ion untuk menghasilkan Ni/MCM-41 dan metode gravimetri untuk uji tingkat keasaman material. MCM-41 yang digunakan untuk sintesis $\mathrm{Ni} / \mathrm{MCM}-41$ memiliki pola difraksi sinar-x dengan struktur heksagonal yang identic dengan hasil dari peneliti MOC. Hasil BET menunjukkan isotherm adsorpsi Langmuir tipe IV dengan luas permukaan material Ni/MCM-41 sebesar $775,9 \mathrm{~m}^{2} / \mathrm{g}$, volume pori sebesar 0,81 cc/g dan jari-jari pori sebesar 15,2 $\mathrm{A}$. Karakterisasi TEM menunjukkan bentuk morfologi Ni/MCM-41 berbentuk struktur heksagonal. Hasil uji tingkat keasaman material Ni/MCM-41 memiliki tingkat keasaman lebih tinggi dibandingkan dengan MCM-41. Berdasarkan data hasil penelitian tersebut maka dapat disimpulkan bahwa Ni/MCM-41 memiliki bentuk morfologi dengan struktur heksagonal, memiliki luas permukaan yang cukup besar serta memiliki ukuran pori yang tergolong material mesopori dan memiliki tingkat keasaman yang lebih tinggi dibandingkan dengan MCM-41 hasil sintesis. 


\section{Pendahuluan}

Pada tahun 1992, Mobil Oil Corporation (MOC) melaporkan bahwa material MCM-41 diketahui sebagai anggota material mesopori M41S [1]. Penemuan kelompok material M41S oleh peneliti MOC dilatarbelakangi oleh kebutuhan industri yang membutuhkan material dengan ukuran pori lebih besar daripada material mikropori seperti zeolit.

Sifat yang dimiliki oleh material mesopori MCM-41 antara lain ukuran pori yang dapat diatur yaitu berkisar antara 2-50 $\mathrm{nm}$ dan memiliki tingkat keasaman material yang rendah $(0,3 \mathrm{mmol} \mathrm{H}+\mathrm{g})$ yang diakibatkan oleh perbandingan jumlah Aluminium (Al) yang sedikit dalam kerangka aluminosilikatnya. Karena keasaman yang sangat rendah ini, maka unsur lain yang dapat bertindak sebagai asam Lewis (aluminium dalam kasus ini) harus dimasukkan [2].

Material mesopori MCM-41 murni tidak dapat digunakan langsung sebagai katalis, sehingga perlu ditambahkan logam atau bukan logam untuk menciptakan sisi asam [3]. Tingkat keasaman MCM-41 dapat dimodifikasi dengan menambahkan logam aluminium [4] dan ion hidrogen [5].

Nikel merupakan logam transisi golongan VIIIB pada Sistem Periodik Unsur. Unsur logam $\mathrm{Ni}$ memiliki elektron-elektron yang belum berpasangan pada orbital $d$ sehingga menyebabkan logam $\mathrm{Ni}$ bersifat paramagnetik. Nikel merupakan logam yang bersifat sebagai asam Lewis karena mampu menerima pasangan elektron bebas dari ligan untuk membentuk senyawa kompleks. Keadaan ini menjadikan logam $\mathrm{Ni}$ dapat berperan aktif dalam reaksi katalitik. Peran aktif tersebut adalah untuk mengadsorpsi reaktan yang telah terdifusi pada permukaan katalis, sehingga dapat mempercepat reaksi. Oleh karena itu, peneliti melakukan penelitian lanjutan yaitu menggunakan logam Ni sebagai logam yang akan ditambahkan pada material mesopori MCM-41 hasil sintesis yang diharapkan dapat meningkatkan tingkat keasamannya.

Penelitian ini bertujuan untuk menghasilkan material mesopori Ni/MCM-41 dan melihat pengaruh penambahan logam
Nikel terhadap tingkat keasaman material mesopori Ni/MCM-41.

\section{Bahan dan Metode \\ Bahan}

Bahan yang digunakan dalam penelitian ini adalah material mesopori MCM-41 yang telah disintesis menggunakan $\mathrm{TMAOH}$ dan garam anorganik $\mathrm{K}_{2} \mathrm{SO}_{4}$ [4], larutan nikel klorida $\left(\mathrm{NiCl}_{2} \cdot 6 \mathrm{H}_{2} \mathrm{O}\right)$ 0,1 M, dan gas hidrogen. Metode

Metode yang digunakan untuk menghasilkan Ni/MCM-41 dalam penelitian ini adalah metode pertukaran ion. Mula-mula, MCM-41 hasil sintesis sebanyak $3 \mathrm{~g}$ direndam ke dalam $50 \mathrm{ml}$ larutan $\mathrm{NiCl}_{2} \cdot 6 \mathrm{H}_{2} \mathrm{O}$ 0,1M dan diaduk perlahan dengan pengaduk magnet menggunakan stirrer selama 4 jam pada suhu ruangan. Padatan yang diperoleh dari campuran larutan disaring dan dikeringkan dalam oven pada suhu $90{ }^{\circ} \mathrm{C}$. Filtrat yang dihasilkan kemudian dianalisis menggunakan Spektroskopi Serapan Atom untuk mengetahui kandungan Ni yang teradsorp pada padatan MCM-41. Padatan yang dihasilkan kemudian direduksi dengan menggunakan tanur pada suhu $450{ }^{\circ} \mathrm{C}$ dengan kenaikan temperatur $1{ }^{\circ} \mathrm{C}$ per 30 detik dengan dialiri udara selama 1 jam dilanjutkan dengan aliran gas $\mathrm{H}_{2}$ selama 3 jam.

Metode yang digunakan untuk uji keasaman adalah metode gravimetri, dengan menghitung daya adsorpsi material terhadap basa. Basa yang sering digunakan adalah $\mathrm{NH}_{3}$, Piridin, Piperidin, quinolin, trimetil amin, dan pirol yang teradsoprsi pada situs asam dengan kekuatan adsorpsi yang proporsional dengan kekuatan asam. Dengan metode ini dapat diukur jumlah gas yang teradsorpsi pada permukaan material. Dalam penelitian ini, penentuan jumlah sisi asam Lewis dan Brønsed dilakukan dengan menggunakan amoniak dan piridin. Proses adsorpsi dilakukan di dalam desikator selama 24 jam pada suhu kamar. Pada proses inilah terjadi adsorpsi dari basa, baik itu amoniak ataupun piridin, dengan permukaan pori dari material.

\section{Hasil dan Pembahasan \\ Karakterisasi MCM-41 \\ Material MCM-41 hasil sintesis telah \\ dikarakterisasi menggunakan karakterisasi}


difraksi sinar-x (XRD) yang dapat dilihat pada Gambar 1. Data pola difraksi sinar-x yang dihasilkan menunjukkan bahwa puncak yang muncul pada sudut $2 \theta$ antara $2 \circ-5^{\circ}$ dapat diindeks menurut sistem kristal heksagonal dengan bidang kristal (100), (110) dan (200) yang identik dengan struktur sistem heksagonal MCM-41 yang dihasilkan oleh peneliti MOC [1].

$2 \theta$ (der)

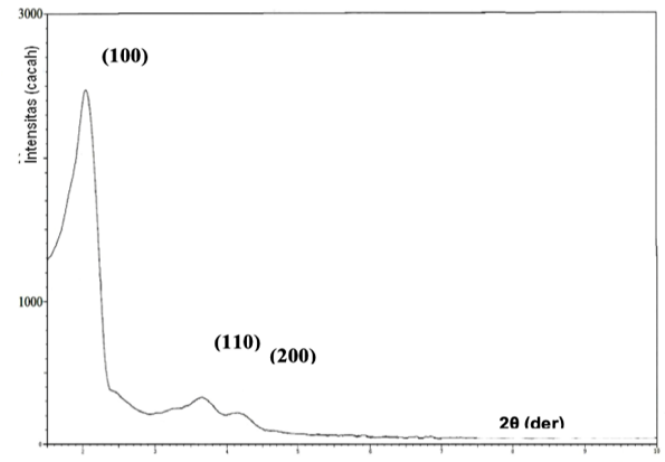

Gambar 1. Pola difraksi sinar-x MCM-41 [3].

\section{Karakterisasi Menggunakan BET}

Karakterisasi menggunakan metode Brunauer-Emmet-Teller (BET) bertujuan untuk mengetahui ukuran pori, luas permukaan, dan distribusi pori pada suatu material. Metode yang paling banyak digunakan untuk mengetahui luas permukaan suatu padatan adalah metode BET [6]. Metode BET ini didasarkan pada suatu model k63inetik dari proses isoterm adsorpsi Langmuir dan merupakan metode yang digunakan dalam penentuan luas permukaan dan distribusi ukuran pori suatu padatan katalis. Material yang dikarakterisasi menggunakan metode BET dalam penelitian ini adalah material mesopori Ni/MCM-41 yang dapat dilihat pada Gambar 2.

Adsorpsi nitrogen material $\mathrm{Ni} / \mathrm{MCM}-41$ yang ditunjukkan pada Gambar 2 mengikuti isoterm adsorpsi Langmuir tipe IV yang merupakan karakteristik untuk material mesopori. Nitrogen yang teradsorpsi pada permukaan material akan bertambah sedikit demi sedikit seiring dengan kenaikan tekanan realtif. Kondensasi kapiler yang menunjukkan adanya mesopori heksagonal mulai terjadi pada tekanan relatif $\left(\mathrm{P} / \mathrm{P}_{0}\right) \quad 0,27 \quad-\quad 0,4$ pada karakterisasi material mesopore Ni/MCM-41. Karakteristik mesopori heksagonal dinyatakan dengan adanya kondensasi kapiler isotermal adsorpsi nitrogen pada tekanan relatif $\left(\mathrm{P} / \mathrm{P}_{0}\right)$ disekitar 0,25 [7]. Berdasarkan data karakterisasi BET diperoleh luas permukaan material Ni/MCM-41 sebesar 775, $9 \mathrm{~m}^{2} / \mathrm{g}$, volume pori sebesar $0,81 \mathrm{cc} / \mathrm{g}$ dan jari-jari pori sebesar 15,2 $\AA$ (diameter pori 30,4 $\AA$ atau 3,04 $\mathrm{nm})$. Data yang diperoleh dari metode BET merupakan data tambahan yang dapat menjelaskan bahwa material Ni/MCM-41 merupakan material mesopori yang memiliki area luas permukaan material yang cukup besar dan juga memiliki ukuran pori sebesar 3,04 nm yang termasuk dalam kelompok mesopori (2-50 $\mathrm{nm})$.

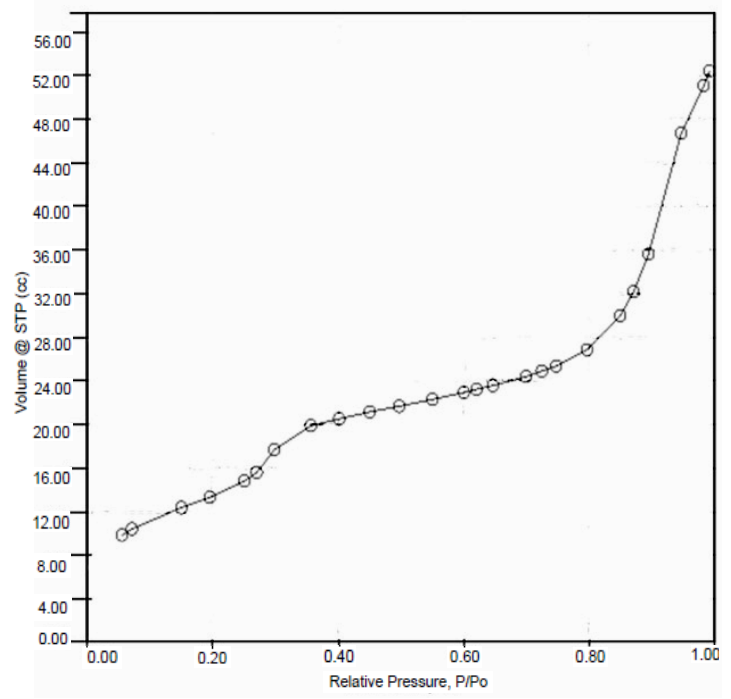

Gambar 2. Isoterm adsorpsi nitrogen pada material $\mathrm{Ni} / \mathrm{MCM}-41$

\section{Karakterisasi Menggunakan TEM}

Karakterisasi menggunakan Transmission Electron Microscope (TEM) bertujuan untuk mengetahui bentuk morfologi dari material Ni/MCM-41. Material mesopori MCM-41 memiliki karakteristik bentuk pori heksagonal [8]. Bentuk morfologi pada Gambar 3 menunjukkan bentuk morfologi Ni/MCM-41 berbentuk heksagonal seperti sarang lebah.

Gambar 3 dapat juga digunakan untuk menghitung ukuran diameter pori material Ni/MCM-41. Metode perhitungan yang dilakukan adalah metode manual dengan cara menghitung perbandingan skala gambar hasil analisis menggunakan TEM dengan panjang diameter pori pada gambar tersebut menggunakan penggaris (mistar ukur). Perhitungan yang dilakukan secara manual memperoleh hasil ukuran diameter pori sebesar 
2,89 nm, jika dibandingkan dengan hasil pengukuran diameter pori menggunakan metode BET sebesar 3,04 $\mathrm{nm}$ maka hasil yang didapatkan tidak jauh berbeda dengan hasil dari perhitungan manual menggunakan metode TEM, sehingga semakin jelas diketahui bahwa sistesis yang dilakukan telah berhasil memperoleh material MCM-41 dengan ukuran pori termasuk dalam golongan mesopori dengan bentuk struktur heksagonal yang seragam.

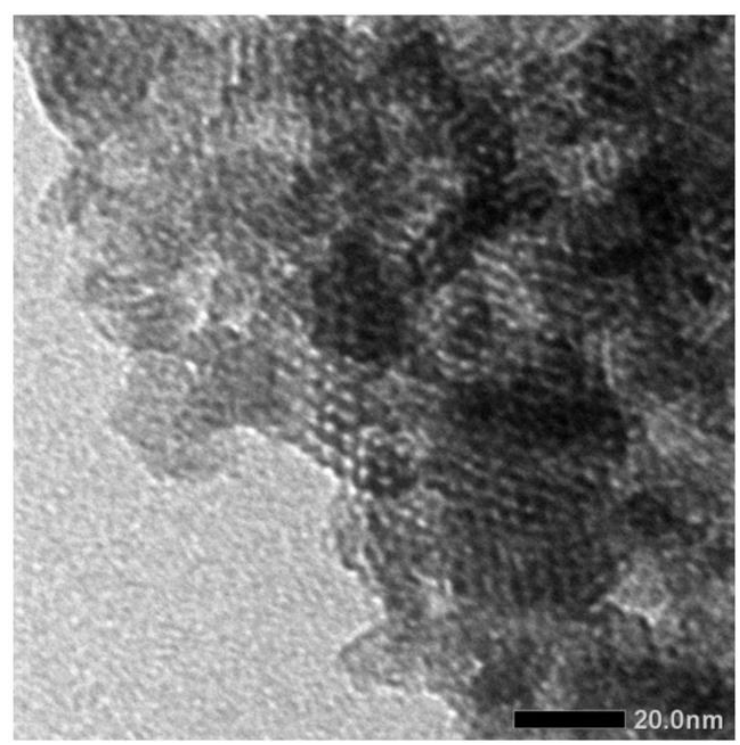

Gambar 3. Bentuk morfologi Ni/MCM-41 menggunakan TEM

\section{Uji Tingkat Keasaman Ni/MCM-41}

Keasaman suatu material dapat diartikan sebagai kekuatan asam, jumlah asam, serta gugus asam Lewis dan asam Brønsted-Lowry. Pada penelitian ini, uji keasaman dilakukan pada material MCM-41 dan Ni/AlMCM-41. Hal ini dilakukan untuk mengetahui pengaruh logam yang diembankan ke dalam struktur MCM-41 terhadap sisi asam Lewis dan Brønsted serta untuk mengetahui kekuatan asamnya.

Tabel 1. Keasaman material MCM-41 dan Ni/MCM-41 menggunakan absorpsi basa

\begin{tabular}{ccc}
\hline \multirow{2}{*}{$\begin{array}{c}\text { Jenis } \\
\text { katalis }\end{array}$} & \multicolumn{2}{c}{ Keasaman Material } \\
\cline { 2 - 3 } & $\begin{array}{c}\text { Amoniak } \\
(\mathbf{m m o l} \\
\left.\text { gram }^{-1}\right)\end{array}$ & $\begin{array}{c}\text { Piridin } \\
\left(\mathbf{m m o l} \text { gram }^{-1}\right)\end{array}$ \\
\hline MCM-41 & 0,8429 & 0,7407 \\
Ni/MCM-41 & 1,1150 & 7,0645 \\
\hline
\end{tabular}

Kandungan asam material MCM-41 dan Ni/MCM-41 dapat dilihat dari banyaknya basa (piridin dan amoniak) yang teradsorp pada material. Hasil uji keasaman material menggunakan adsorpsi basa piridin dan amoniak mendapatkan hasil adsorpsi sebagaimana disajikan dalam Tabel 1.

Data pada Tabel 1 dapat dilihat bahwa adsorpsi basa piridin pada material mesopori MCM-41 indentik dengan kandungan situs asam Lewis pada material, sedangkan adsorpsi basa amoniak lebih identik terhadap situs asam Brønsted yang terkandung pada material. Berdasarkan data keasaman tersebut maka dapat dikatakan bahwa material Ni/MCM-41 merupakan material dengan tingkat keasaman yang lebih tinggi dibandingkan MCM-41 dan memiliki kandungan situs asam Lewis lebih banyak daripada kandungan situs asam Brønsted. Perhitungan uji keasaman material menggunakan persamaan keasaman dimana w1 merupakan berat wadah kosong (gr); w2 merupakan berat wadah ditambah sampel (gr); w3 merupakan berat uji material (gr); dan $\mathrm{Mr}=$ berat molekul basa (amoniak/piridin).

$$
\text { Keasaman }=\frac{\left(W_{3}-W_{2}\right)}{\left(W_{2}-W_{1}\right) M r} m o l ~ g r^{-1}
$$

\section{Ucapan terimakasih}

Terima kasih kepada Prof. Dr. Iip Izul Falah yang banyak membantu peneliti sehingga penelitian ini dapat dilaksanakan dan menghasilkan produk penelitian yang baik dalam pengembangan pembuatan material mesopori MCM-41.

\section{Kesimpulan}

Berdasarkan data hasil penelitian maka dapat disimpulkan bahwa Ni/MCM-41 memiliki bentuk morfologi dan pola difraksi sinar-x dengan sistem struktur heksagonal, memiliki luas permukaan $775,9 \mathrm{~m}^{2} / \mathrm{g}$, volume pori sebesar $0,81 \mathrm{cc} / \mathrm{g}$ dan jari-jari pori sebesar $15,2 \AA$ (diameter pori $3,04 \mathrm{~nm}$ ) dan memiliki tingkat keasaman yang lebih tinggi dibandingkan dengan MCM-41 hasil sintesis. 


\section{Daftar Pustaka}

1. Kresge, C. T., Leonowicz, M. E., Roth, W. J., Vartuli, J. C., Beck, J. S., Ordered Mesoporous Molecular Sieves Synthesized by a Liquid Crystal Template Mechanism, J. Nature, 1992, 359, 710-712.

2. Suyanta, S., Falah, I. I., Cracking of Palm Oil over H-AIMCM-41 Catalyst, J. Chem. Chem. Eng., 2012, 6, 531-535.

3. Bhattacharyya, K. G., Anup, K., Taklukdar A. K., Parashmani, D., and Sivasanker, S., Acetylation of Phenol with Al-MCM-41, Catalysis Communication, 2001, 2, 105-111.

4. Tengker, S., Falah, I., Sintesis dan karakterisasi material mesopori MCM-41 menggunakan TMAOH dan garam anorganik K2SO4. Fullerene Journal Of Chemistry, 2017, 2(2), 61-65.

5. Tengker, S., Falah, I., Analisis pengaruh penambahan ion $\mathrm{H}+$ pada sintesis material mesopori Al-MCM-41 menjadi H-MCM41. Fullerene Journal Of Chemistry, 2018, 3(1), 9-12.

6. Sutarno, Arryanto, Y., Wigati, S., Pengaruh Rasio Mol Si/Al Larutan Prekusor pada Karakter Struktur MCM-41 dari Abu Layang, Ind. J. Chem., 2003, 3(2), 126-134.

7. Hsu, C. H., Wang, Y. L., Ko, A. N., Liquid Phase Hydrogenation of $t, t, c-1,5,9-$ Cyclododecatriene Over Ni/MCM-41 and $\mathrm{Ni} / \mathrm{SiO}_{2}$ Catalysts. Journal of the Chinese Chemical Society, 2009, 56, 908-915.

8. Beck, J. S., Vartuli, J. C., Roth, W. J., Leonowicz, M. E., Kresge, C. T., Schmitt, K. D., Chu, C. T. W., Olson, D. H., Sheppard, E. W., A new family of mesoporous molecular sieves prepared with liquid crystal templates, Journal of the American Chemical Society, 1992, 114(27), 1083410843. 